Journal of

Education and Practice

(JEP)

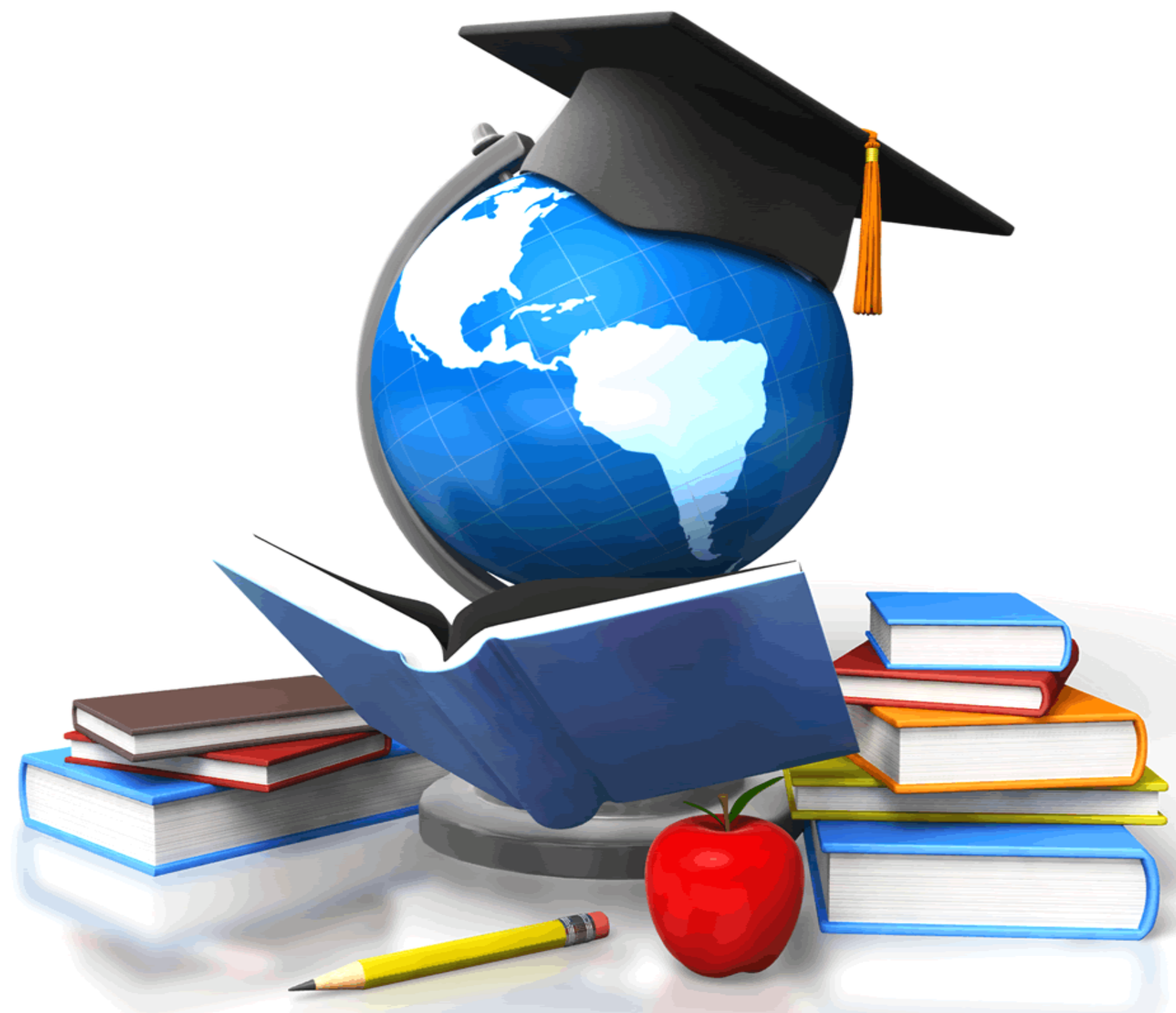

CARI 


\title{
EFFECT OF FORMATIVE CLASSROOM ASSESSMENT IN SAUDI ARABIAN
}

\section{ELEMENTARY SCHOOLS}

\author{
$1^{*}$ May Alashwal \\ *Department of Learning Sciences and Educational Research, University of Central \\ Florida, \\ Orlando, FL, Orlando, FL 32816, USA \\ Corresponding author Email: msalashwal@knights.ucf.edu
}

\begin{abstract}
Purpose: This study investigates the effect of formative classroom assessment (FCA) on elementary school pupils in Saudi Arabia.

Methodology: The duration of the study covered one entire academic year. The work was based on an experimental design of two tests: pre- and post-test. The number of participants was 120 pupils of mixed gender. The participants were purposively sampled for this study. The study's two tests were based on the Basic Science Achievement Test (BSAT). The pupil's test feedback was validated by experienced teachers in the field.

Results: The results demonstrated that FCA had a significant effect on elementary school pupils by improving academic test scores. This research further showed that FCA had an increased positive effect on female pupils' academic exam scores when compared to male pupils.

Contribution to Theory Policy and Practice: The study recommends enforcing regular and continuous FCA for elementary-level school pupils with appropriate and adequate FCA training for teachers in order to improve pupils' academic achievements.
\end{abstract}

Keywords: Elementary school; formative classroom assessment; Teachers training; classroom; Basic Science Achievement Test

\section{INTRODUCTION}

The learning process of elementary school pupils takes place in a classroom, which is merely a training environment. The classroom contains a mixed, dynamic system of interactions among teachers and pupils. Teachers in classrooms take the burden of instructing the pupils in order to determine pupils' level of learning and academic achievements. In the classroom setting, teachers need to realize that their pupils' level of competencies are related to their year grade and how they can improve these competencies based on their year-long instructions. Situated within this context is the importance of classroom assessment by continuously collecting information about pupils, academic programs, and educational policies (Lambert, 2020). An educational system in any country must maintain a continuous assessment of pupils' progress and achievements, particularly 
in a dynamic world with many rapid developments and changes that require new skills, training, and abilities (Koksalan \& Ogan-Bekiroglu, 2019). Therefore, the assessments must be changed periodically at both high (i.e., school) and low (i.e., classroom) levels (Dilekli, 2017). Assessments should be seen as a process of a systematic well-set measurement that assists teachers in reaching solid and clear judgments about their pupils. The teachers' judgment about their pupils must be continuously updated by a well-made classroom assessment.

The classroom assessment information-collecting tools include performance ratings, paper \& pencil tests, interviews, project ratings, and observations. Teachers can provide updated feedback related to the performance and progress of pupils to their parents via classroom assessment results. Classroom assessment can also assist in providing reliable decisions about pupils, determining their knowledge level, providing a supportive learning atmosphere, assessing individuals' learning progress and competency, and diagnosing classroom problems (Archila, Molina, \& Truscott de Mejía, 2018). FCA is a form of classroom assessment that involves raising one or two simple sentences that summarize the main point of a lesson during class. It helps in planning the course ahead and verifies any current learning difficulties. The second form of classroom assessment includes the Summative Classroom Assessment (SCA) that includes written exams, research paper, or a capstone project that is performed at the end of the program. The third form of classroom assessment is the Placement Classroom Assessment (PCA), which determines the level of pupils' knowledge before entering a new classroom level. The role of a classroom teacher should include monitoring the pupils' growing competence and learning progress.

FCA is a continuous activity that is used by teachers and pupils during lessons in classrooms that improve pupils' lesson understanding and outcomes. This approach provides instant feedback on the ongoing lesson (Bennett, 2011; Stronge, 2018). FCA is a powerful tool for pupils and teachers. FCA assists pupils by identifying their learning difficulties and provides a method to improve their academic achievements. FCA also assists teachers by determining where pupils face difficulties in the lesson and forecasting a better teaching strategy that results in better academic achievements (Moyosore, 2015; Ojugo et al., 2013). The key to a successful FCA is to use the quality assessment tools and the subsequent use of the FCA results (Ugodulunwa \& Okolo, 2015). FCA is an assessment for learning that is set and designed mainly to improve pupils' learning (Alghamdi \& Hamed Alanazi, 2019; Danniels, Pyle, \& DeLuca, 2020).

William et al. noted that pupils' achievements can be enhanced by an assessment for learning, which is used by both teachers and pupils. Moreover, this approach identifies any areas where pupils encounter difficulties, which can then be worked upon (Wiliam*, Lee, Harrison, \& Black, 2014). Studies show that FCA demands careful design by teachers in order to help them utilize the resulting information to determine pupils' knowledge and when and how to apply that knowledge; this strategy can be used to improve pupils' learning process by providing them with reliable feedback. One of the advantages of FCA is the provision of instant feedback for teachers and pupils related to the learning process, demonstrating any gaps between pupils' knowledge in classrooms and teacher's expectations (Matilda \& Helen, 2019). Given the importance of FCA, research on the effect of using such assessment on elementary schools in Saudi Arabia is limited. There seemed to be a gap in research that investigate the effectiveness of FCA in Saudi Arabia elementary schools. 
In order to help improving pupils' learning and academic achievement, the results from a welldesigned FCA can provide guidance and information on how and what areas of a specific subject matter that need to be improved. Therefore, a study on the effect of FCA on elementary pupils' academic achievement can provide insightful information on the learning process. The objective of this study is to determine the effect of FCA in Saudi Arabian elementary schools. The work aims to show the quantitative improvement of pupils at the elementary level by using this particular assessment approach. It also aims to analyze the different effects of FCA on females and male pupils and determine its significance.

\section{Research Question}

This research aims to answer the following questions:

Research Question 1: What is the effect of formative classroom assessment in Saudi Arabian elementary schools?

Research Question 2: What are the different effects of FCA on females and male pupils and its significance?

\section{METHODOLOGY}

\section{Research Design and Sampling}

The research design in this study is based on both pre- and post-test experimental designs. The number of participants (pupils) in the study was 120 from two private elementary schools (randomly selected) in Jeddah, Saudi Arabia. Participants were selected based on their scores. The pupils in this study scored less than $60 \%$ in their first (fall) semester. The FCA tests were applied in their second semester. The Basic Science Achievement Test (BSAT) comprised 5 multiplechoice questions (MCQ) for the pre- and post-test of selected subjects; MCQs were validated by expert teachers in the subject.

\section{Study Procedure}

Participants were tested (pre-test) with the BSAT in week one of the second term. Pupils were selected based on their poor scores in their previous semester (below 60\%). In their second semester, the pupils received a demonstration class of the experiment and the FCA strategy. The researcher presented the MCQs for 2 minutes in each class, after the lesson, for 3 classes a week for 15 weeks. MCQs were solved together after each class through a provoking question, and a copy was given back to the pupils. Sufficient time was provided to allow pupils to discuss what they had learned in class. Data were recorded weekly for each pupil to monitor their performance.

\section{Participants profile}

There were 120 participants from 4 different levels at two elementary schools. Table 1 shows participant profiles and their frequency. 
Journal of Educatio and Practice

ISSN 2520-467X (Online)

Vol, 4. Issue No.1 pp18 - 27, 2020

Table 1: Participant profiles

www.carijournals.org

\begin{tabular}{lcc}
\hline Variable & Value & Participants \\
\hline Gender & Male & 64 \\
& Female & 56 \\
\hline Grades & $1^{\text {st }}$ grader & 23 \\
& $2^{\text {nd }}$ grader & 28 \\
& $3^{\text {rd }}$ grader & 34 \\
& $4^{\text {th }}$ grader & 35 \\
\hline Participants & School \# 1 & 54 \\
& School \# 2 & 66 \\
\hline Pupils scores in semester one & $10-20 \%$ & 2 \\
& $20-30 \%$ & 18 \\
& $30-40 \%$ & 27 \\
& $40-50 \%$ & 26 \\
& $50-60 \%$ & 47 \\
\hline
\end{tabular}

\section{RESULTS AND DISCUSSION}

Data were collected from students who were on a 1-year academic course, including a subsequent follow-up collection. Pupils' scores were compared between first and second semesters. The FCA took place in the second semester and had a significant effect on pupils. The results in Table 2 show that pupils' class scores also improved for both genders when applying FCA in the $2^{\text {nd }}$ semester compared to their class scores in the $1^{\text {st }}$ semester.

Table 2: Pupils' response to $2^{\text {nd }}$-semester improvement change's effect of using FCA by gender

\begin{tabular}{lccc}
\hline Study perception (120 pupils) & Female pupils & Male pupils & Dev. \\
\hline Saves teachers' teaching time & $24.3 \%$ & $19.3 \%$ & 0.205 \\
Improves pupil's scores & $81.7 \%$ & $59.2 \%$ & 0.269 \\
Improves pupil's satisfaction with classroom & $88.2 \%$ & $62.8 \%$ & 0.288 \\
Improves pupil-pupil interaction & $22.7 \%$ & $15.1 \%$ & 0.335 \\
Improves teachers' satisfaction with classroom & $42.3 \%$ & $19.3 \%$ & 0.544 \\
Improves teacher-pupil interaction & $66.2 \%$ & $56.7 \%$ & 0.144 \\
Decreases study time at home & $72.4 \%$ & $55.4 \%$ & 0.266 \\
Improves pupil's ability to understand & $68.4 \%$ & $49.4 \%$ & 0.323 \\
\hline
\end{tabular}

The results of the study per school are provided in Table 3. Table 3 shows that pupils' class scores improved when applying FCA in the $2^{\text {nd }}$ semester compared to their class scores in the $1^{\text {st }}$ semester. 
The results of the two schools were relatively similar for all study perceptions. Applying FCA to elementary school pupils reduced teachers' teaching time by $19.8 \%$ and improved pupils' scores by $70.7 \%$. This approach also improved pupils' satisfaction with the classroom by $71.8 \%$ and improved pupil--to-pupil interaction by $39.3 \%$. Teacher satisfaction with the classroom also increased by $37.9 \%$, and teacher-to-pupil interactions were $91.3 \%$ higher. A questionnaire sent to pupil's parents shows that there was a decrease in pupils' study time at home by $28.9 \%$, and their ability to comprehend the class lesson increased by $75.4 \%$.

Table 3: Pupils' response to $2^{\text {nd }}$-semester improvement change's effect of using FCA by school

\begin{tabular}{lccc}
\hline Study perception (120 pupils) & $\begin{array}{c}\text { School } \\
\mathbf{\# ~ 1}\end{array}$ & $\begin{array}{c}\text { School } \\
\mathbf{\#} \text { 2 }\end{array}$ & Mean \\
\hline Saves teachers' teaching time & $13.3 \%$ & $26.3 \%$ & $19.8 \%$ \\
Improves pupil's scores & $71.4 \%$ & $69.6 \%$ & $70.7 \%$ \\
Improves pupil's satisfaction with classroom & $78.2 \%$ & $65.3 \%$ & $71.8 \%$ \\
Improves pupil-pupil interaction & $42.7 \%$ & $35.8 \%$ & $39.3 \%$ \\
Improves teachers' satisfaction with classroom & $32.3 \%$ & $43.6 \%$ & $37.9 \%$ \\
Improves teacher-pupil interaction & $96.4 \%$ & $86.2 \%$ & $91.3 \%$ \\
Decreases study time at home & $22.4 \%$ & $35.4 \%$ & $28.9 \%$ \\
Improve pupil's comprehension ability & $63.1 \%$ & $87.6 \%$ & $75.4 \%$ \\
\hline
\end{tabular}

Results for both genders (Table 2) were not as close as those results outlined in Table 3 for all study perceptions. Applying FCA to elementary school pupils was found to reduce teachers' teaching time by $21.8 \%$ and improve pupils' scores by $70.5 \%$. The FCA also increased pupils' satisfaction with the classroom by $75.5 \%$ and improved pupil-to-pupil interaction by $18.9 \%$. This approach also improved teachers' satisfaction with the classroom by $30.8 \%$ and increased teacherto-pupil interaction by $61.5 \%$. A questionnaire sent to pupil's parents demonstrated a decrease in pupil's study time at home by $63.9 .9 \%$, and their ability to comprehend the class lesson increased by $58.9 \%$. Similarly, Table 4's results show a similar trend as for the results in the previous tables.

There were improvements for all perceptions in this study. In general, the performance of the pupils of both genders increased. The effect of FCA in classrooms gave good indicators to teachers regarding how they can increase their pupils' understanding during class and how this approach can substantially impact their pupil's academic achievements. This investigation demonstrated a significant improvement in the test scores between $1^{\text {st }}$ and $2^{\text {nd }}$-semester scores on different levels for both genders. The FCA improved pupils' performance, and their scores therefore increased 
Journal of Educatio and Practice

ISSN 2520-467X (Online)

Vol, 4. Issue No.1 pp18 - 27, 2020

www.carijournals.org

significantly. Hence, the pupils were demonstrated to have experienced a deeper conceptual understanding of their classroom lessons.

Table 4: Pupils' response to $2^{\text {nd }}$-semester improvement change's effect of using FCA by elementary grade

\begin{tabular}{lcccc}
\hline Study perception (120 pupils) & $\begin{array}{c}\mathbf{1}^{\text {st }} \\
\text { grade }\end{array}$ & $\begin{array}{c}\mathbf{2}^{\text {nd }} \\
\text { grade }\end{array}$ & $\begin{array}{c}\mathbf{3}^{\text {rd }} \\
\text { grade }\end{array}$ & $\begin{array}{c}\mathbf{4}^{\text {th }} \\
\text { grade }\end{array}$ \\
\hline Saves teachers' teaching time & $29.3 \%$ & $28.3 \%$ & $23.8 \%$ & $20.8 \%$ \\
Improves pupil's scores & $81.7 \%$ & $79.2 \%$ & $70.5 \%$ & $73.4 \%$ \\
Improves pupil's satisfaction with classroom & $88.2 \%$ & $76.8 \%$ & $75.5 \%$ & $77.3 \%$ \\
Improves pupil-pupil interaction & $22.7 \%$ & $27.1 \%$ & $28.9 \%$ & $28.1 \%$ \\
Improves teachers' satisfaction with classroom & $42.3 \%$ & $38.3 \%$ & $30.8 \%$ & $34.2 \%$ \\
Improves teacher-pupil interaction & $66.2 \%$ & $60.7 \%$ & $61.5 \%$ & $60.8 \%$ \\
Decreases study time at home & $72.4 \%$ & $67.4 \%$ & $63.9 \%$ & $67.2 \%$ \\
Improves pupil's understanding ability & $68.4 \%$ & $49.4 \%$ & $58.9 \%$ & $48.8 \%$ \\
\hline
\end{tabular}

The FCA appears, therefore, to be an effective method for promoting pupil's comprehension and enhancing their academic achievements. This study's results are in accordance with other research demonstrating that FCA is significantly effective for elementary-level pupils and helps teachers allocate and diagnose their pupil's difficulties and therefore improves their academic achievements (Alahmadi, Alrahaili, \& Alshraideh, 2019; Gallo, 2019; Gustafson, Nordström, Andersson, Fälth, \& Ingvar, 2019; Moyosore, 2015; Rakoczy et al., 2019; Simon, 2019; Wiliam* et al., 2014). One particularly impressive aspect of the FCA is the instant feedback it provides to pupils, such that they can determine their weak points in the learning process due to the close teacher supervision. Consequently, pupils have a tendency to learn and enhance their understanding in order to gain higher scores in tests and eventually improve their academic achievement. The application of FCA clarifies the pupils' vision by allowing them to assess their current position in the learning process, their aims and goals, and what they need to do to achieve higher academic scores (Oti, Ariya, \& Salau, 2020; Sahibzada \& Himat, 2019).

This study revealed a moderate and significant difference in gender regarding the effect of FCA on pupils' scores. The FCA significantly improved the females' scores and academic achievements more than it did for males. Both genders improved substantially, but not to the same degree. There was a difference in pupils of both genders' scores that was not dependent on FCA but rather due to gender differences. Females performed better with FCA than males throughout the study. 
Finally, the study analysis revealed no significant difference among the four elementary levels, as illustrated in Table 4 . However, the $1^{\text {st }}$ graders' scores improved more than the $2^{\text {nd }}$ graders, and so on. Hence, pupils' age clearly did not affect the FAC results. The conclusion drawn from Table 4 is that the younger pupils are, the more FCA becomes effective.

\section{CONCLUSION AND RECOMMENDATIONS}

\section{Conclusion}

This research aimed to determine the effect of FCA on elementary-level pupils in Saudi Arabian schools. The work determined the effect of FCA in Saudi Arabian elementary schools with respect to a variety of perceptions. There was found to be a quantitative improvement of pupils at the elementary level by applying FCA in classrooms. Various effects of FCA on female compared to male pupils were also noted.

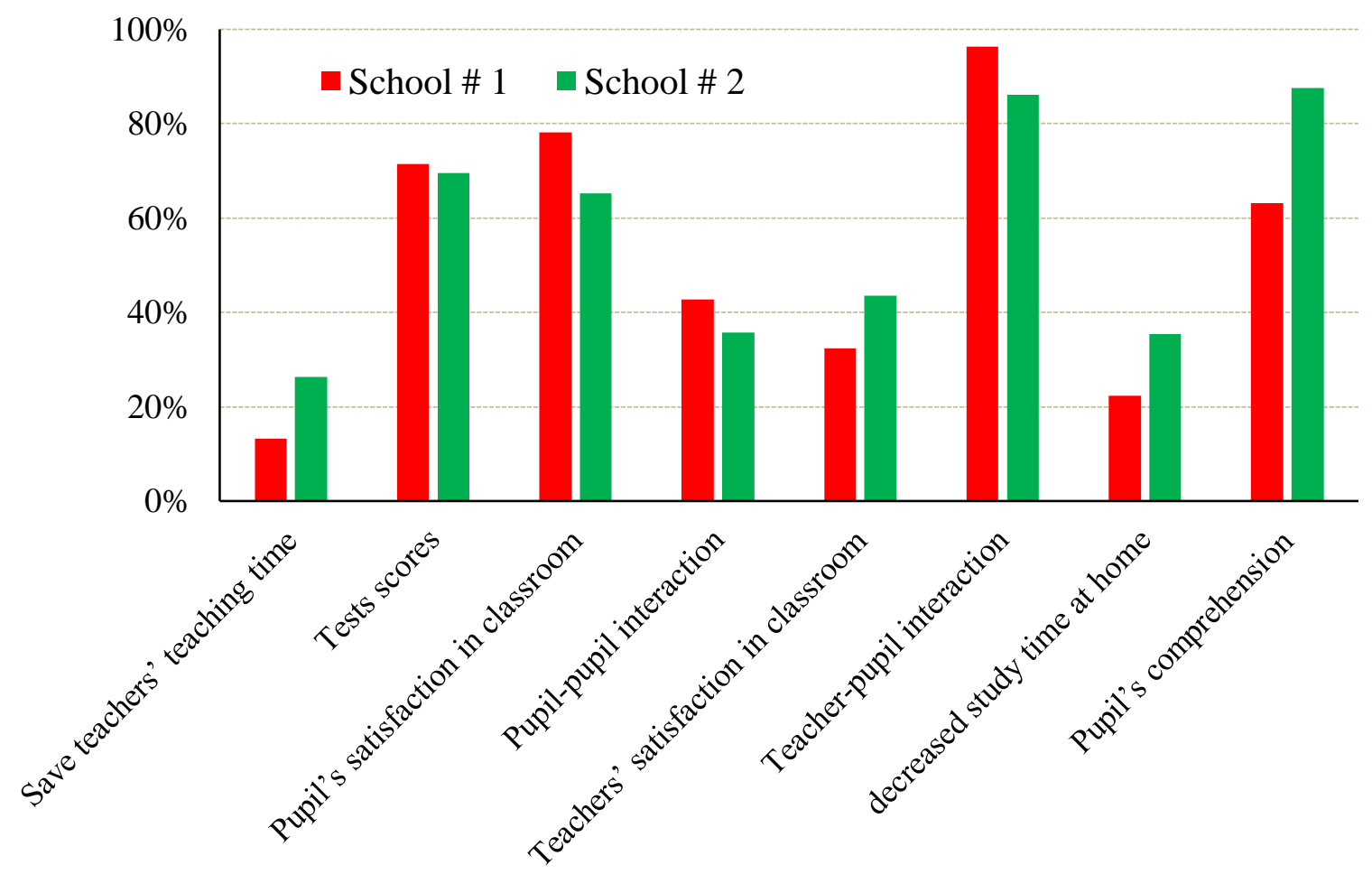

Figure 1: Effect by school with respect to $2^{\text {nd }}$-semester improvement change's when applying FCA in classrooms.

Teachers require assessment tools to make important decisions related to the daily educational process. Assessments are vital for the instructional and educational decisions that are involved in analyzing the teaching and learning process (Figure 1). This research has demonstrated the importance of applying FCA in classrooms. This assessment approach was found to have a substantial effect on pupils' academic achievements, regardless of gender. The study further 
Journal of Educatio and Practice

ISSN 2520-467X (Online)

Vol, 4. Issue No.1 pp18 - 27, 2020

www.carijournals.org

asserts that teachers committed to FCA, with an ability to provide instant feedback for pupils, leads to a significant improvement in these students' academic achievements.

\section{Recommendations}

The three recommendations based on this study are as follows:

1- Provide intense training courses to elementary-level teachers to allow them to become familiar with the FCA strategies and its various mechanisms. The training course should also include how to provide adequate feedback for pupils and train teachers regarding solving strategies for pupils' difficulties in learning.

2- Enforce FCA in elementary classrooms due to the fact that this assessment approach has been found to improve pupils' academic achievements. The enforcement can be set along with incentives and attendance at international conferences and seminars.

3- Establish an FCA implementation performance measurements center to provide the Ministry of Education with yearly performance reports of pupils and a close follow-up with teachers.

\section{References}

Alahmadi, N., Alrahaili, M., \& Alshraideh, D. (2019). The Impact of the Formative Assessment in Speaking Test on Saudi Students' Performance. Arab World English Journal (AWEJ) Volume, 10.

Alghamdi, A. K. H., \& Hamed Alanazi, F. (2019). Creating scientific dialogue through social media: exploration of Saudi pre-service science teachers. Research in Science \& Technological Education, 37(4), 471-491.

Archila, P. A., Molina, J., \& Truscott de Mejía, A.-M. (2018). Using formative assessment to promote argumentation in a university bilingual science course. International Journal of Science Education, 40(13), 1669-1695.

Bennett, R. E. (2011). Formative assessment: A critical review. Assessment in education: principles, policy \& practice, 18(1), 5-25.

Danniels, E., Pyle, A., \& DeLuca, C. (2020). The role of technology in supporting classroom assessment in play-based kindergarten. Teaching and Teacher Education, 88, 102966.

Dilekli, Y. (2017). The relationships between critical thinking skills and learning styles of gifted students. European Journal of Education Studies.

Gallo, D. J. (2019). Formative assessment practices and children's singing accuracy: A mixed methods inquiry. International Journal of Music Education, 37(4), 593-607.

Gustafson, S., Nordström, T., Andersson, U. B., Fälth, L., \& Ingvar, M. (2019). Effects of a formative assessment system on early reading development. Education, 140(1), 17-27.

Koksalan, S., \& Ogan-Bekiroglu, F. (2019). Embedding Formative Assessment in Inquiry-Based Learning. RESEARCH HIGHLIGHTS IN EDUCATION AND SCIENCE 2019, 15. 
Lambert, R. G. (2020). Shaping a Validity Argument for the Use of Authentic Formative Assessments to Support Young Children. In Handbook of Research on Formative Assessment in Pre-K Through Elementary Classrooms (pp. 49-69): IGI Global.

Matilda, U. O., \& Helen, A. O. (2019). Effect of Formative Classroom Assessment on Students' Academic Achievement in Junior Secondary School Basic Science in Egor Local Government Area of Edo State, Nigeria.

Moyosore, O. A. (2015). The effect of formative assessment on students' achievement in secondary school mathematics. International Journal of Education and Research, 3(10), 481-490.

Ojugo, A. A., Ugboh, E., Onochie, C. C., Eboka, A. O., Yerokun, M. O., \& Iyawa, I. J. B. (2013). Effects of Formative Test and Attitudinal Types on Students' Achievement in Mathematics in Nigeria. African Educational Research Journal, 1(2), 113-117.

Oti, G. O., Ariya, A. D., \& Salau, H. U. (2020). Effects of Formative Assessment Strategy on Post Basic Students' Attitude and Achievement in Social Studies in Katsina Metropolis, Nigeria. KIU Journal of Social Sciences, 5(4), 365-376.

Rakoczy, K., Pinger, P., Hochweber, J., Klieme, E., Schütze, B., \& Besser, M. (2019). Formative assessment in mathematics: Mediated by feedback's perceived usefulness and students' self-efficacy. Learning and Instruction, 60, 154-165.

Sahibzada, J., \& Himat, A. N. (2019). Impacts of Formative Assessment on EFL Students' Academic Performance at Kandahar University. American International Journal of Social Science Research, 4(2), 102-111.

Simon, B. (2019). The Effect of Formative Assessment on Student Motivation and SelfRegulation.

Stronge, J. H. (2018). Qualities of effective teachers: ASCD.

Ugodulunwa, C., \& Okolo, U. P. (2015). Effects of formative assessment on mathematics test anxiety and performance of senior secondary school students in Jos, Nigeria. IOSR Journal of Research \& Method in Education (IOSR-JRME), 5(2), 38-47.

Wiliam*, D., Lee, C., Harrison, C., \& Black, P. (2014). Teachers developing assessment for learning: Impact on student achievement. Assessment in education: principles, policy \& practice, $11(1), 49-65$. 